\title{
The study of SA on breaking forced dormancy of Ziziphus jujuba 'Zhanshanmizao' and the effects on fruit quality
}

\author{
Guojing Cai ${ }^{1, a}$, Jie Zhou ${ }^{1, b}$, Yan Zhou ${ }^{1, c}$, and Qunxian Deng ${ }^{1, d *}$ \\ ${ }^{1}$ College of Horticulture, Sichuan Agricultural University, Chengdu, Sichuan, China \\ accaiguojingcc@163.com, b493137598@qq.com, czhouyan6213500@qq.com, \\ d1324856299@qq.com \\ ${ }^{*}$ Corresponding author.
}

Keywords: bud breaking chemicals; rice dates; forced dormancy; Organic nutrients; antioxidant system

Abstract. 7-year-old trees of Ziziphus jujuba 'Zhanshanmizao' were used to study physiological indexes. Using SA spray the trees with different concentrations in January 30 th, 2017. Study the changes of water, Organic nutrients (starch, soluble sugar, soluble protein, and free amino acid) and antioxidant system (SOD, POD, $\mathrm{O}_{2-}$, and MDA). Then, measure the fruit quality, The effects of salicylic acid (SA) with different concentrations On breaking forced dormancy of Z. jujuba 'Zhanshanmizao' trees were compared. The results showed that in the forced rest period (form 30 th January till 14 th February) the effect on gibberellin at $200 \mathrm{mg} / \mathrm{L}$, potassium nitrate at $6 \%$ and SA $\mathrm{d}$ do $\mathrm{mmol} / \mathrm{L}$ breaking forced dormancy were better than others, they can improve the ratio of the free water and the bound water significantly. Change the content of organic nutrient composition rapidly, Active the antioxidant system. SA ( $2 \mathrm{mmol} / \mathrm{L})$ had little effect on dormancy-release.

\section{Introduction}

Ziziphus jujuba 'Zhanshanmizao' (Ziziphus jujuba Mill.) as deciduous fruit trees has a long history of cultivation and is rich in a variety of nutritious substances [1]. Z. jujuba 'Zhanshanmizao' is excellent fresh jujube with local characteristics that is quite popular in the market [2]. The dormancy of deciduous fruit trees is divided into correlative dormancy, endodormancy and forced dormancy [3]. Forced dormancy is the dormancy caused by external environment such as low temperature, drought and other stress factors. When plants break away from this adversity, the dormancy of buds will naturally be relieved. In recent years, the study of using chemicals instead of low-temperature chilling requirement to break the forced dormancy of deciduous fruit trees is relatively more [4]. However, study on the physiology of breaking the Z. jujuba 'Zhanshanmizao' forced dormancy has rarely been reported so far. Salicylic acid (SA) is currently used as dormancy-breaking chemicals in the dormancy study of deciduous fruit trees in China. Therefore, in this study, 7-year-old Z. jujuba 'Zhanshanmizao' trees were used as materials to study the changes of water content and organic nutrients in jujube branches treated with different concentrations of SA. And the fruit quality which was sprayed with the dormancy-breaking chemicals was analyzed. The aim of this study is to find the most effective concentration of SA to break the forced dormancy of jujube, advance the maturity of jujube, and increase the income of jujube farmers. It can provide some guidance for the regulation of the ripening period of the regulatory. 


\section{Materials and Methods}

Materials. The experimental base was located in Yonglian village, Yongxin town, Santai county, Mianyang city. The tested materials were 7-year-old Z. jujuba 'Zhanshanmizao' trees (tiller propagation seedlings).

Methods. Plants were treated with four concentrations of SA on January 30 th, 2017, taking 0 $\mathrm{mmol} / \mathrm{L} \mathrm{SA}$ as the control (CK). Each plot was repeated 3 times, with a total of 12 plants in random plot. First samples were taken on the second day after treatment, and then sampled at intervals of 7 d. At each sampling, two or three representative secondary branches in the middle and upper part of the crown of jujube trees were removed. The samples were wrapped in plastic wrap and placed in ice box to the comprehensive laboratory of Horticulture Department, Sichuan Agricultural University. The bark with buds taken by the blade was placed in the refrigerator at $-10{ }^{\circ} \mathrm{C}$ for determination. The changes of water content and organic nutrients (starch, soluble sugar, soluble protein, and free amino acid) were analyzed [5-7]. When the fruits are ripe, 30 fruits were harvested per treatment for fruit quality analysis, including titratable acid, ascorbic acid, and soluble solids [8].

\section{Results and Discussion}

Changes of Water Content. The total water content of jujube bark had been relatively stable since the beginning of experiment, and had a small upward trend (Fig. 1). The change range of total water content and free water content treated with dormancy-breaking chemicals was always higher than that of $\mathrm{CK}$. The change trend of total water content and free water content at different concentrations of SA was basically the same within 15 days after treatment. After the treatment of 15 days with different concentrations of SA,the effect of the total water content tend to converge.

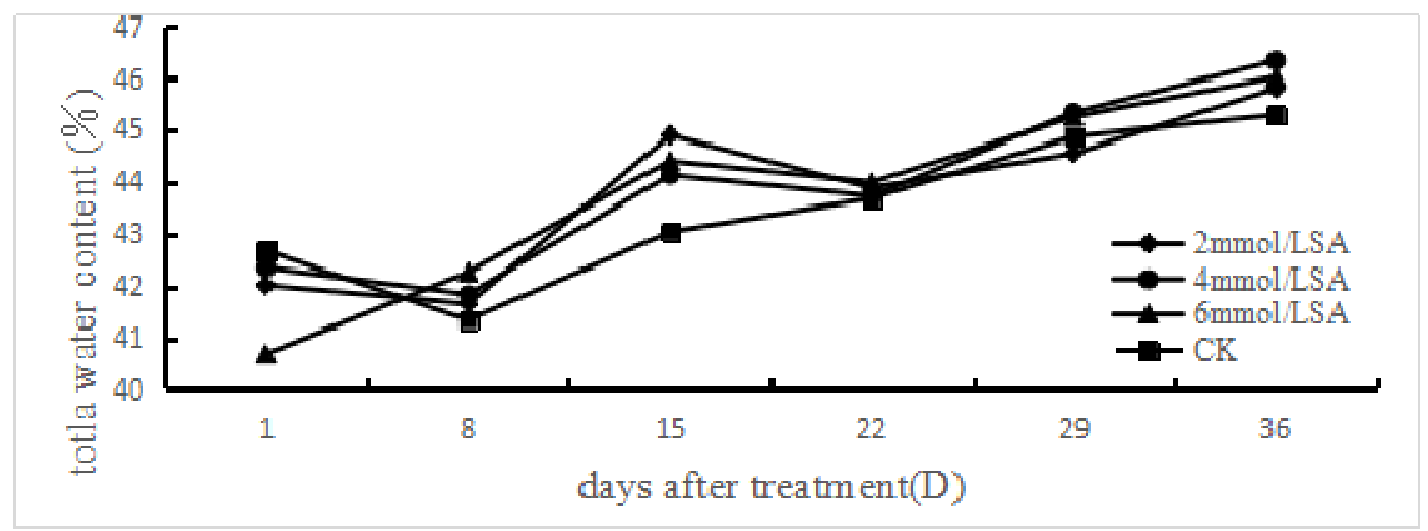

Fig.1 Effects of SA on water content of jujube in dormancy period

During the period of forced dormancy, bound water content in the jujube bark was decreasing, which was just opposite to that of free water. Since 15 days after experiment, the variation trend of various water contents in the bark of all jujubes treated by SA was significantly better than that of $\mathrm{CK}$, which may be related to the enhancement of the metabolic activity of the trees. The decrease of bound water content and the ratio of bound water to free water indicated the end of the jujube tree's forced dormancy. 


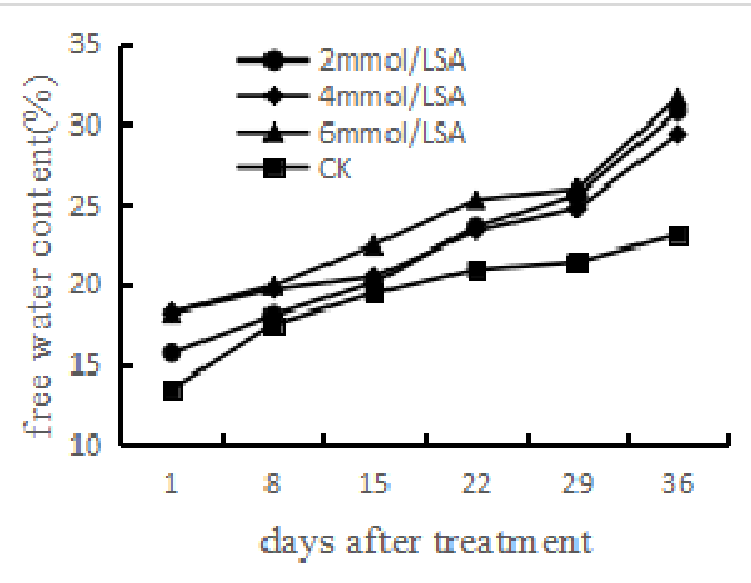

Fig.2 Effects of SA on free water content

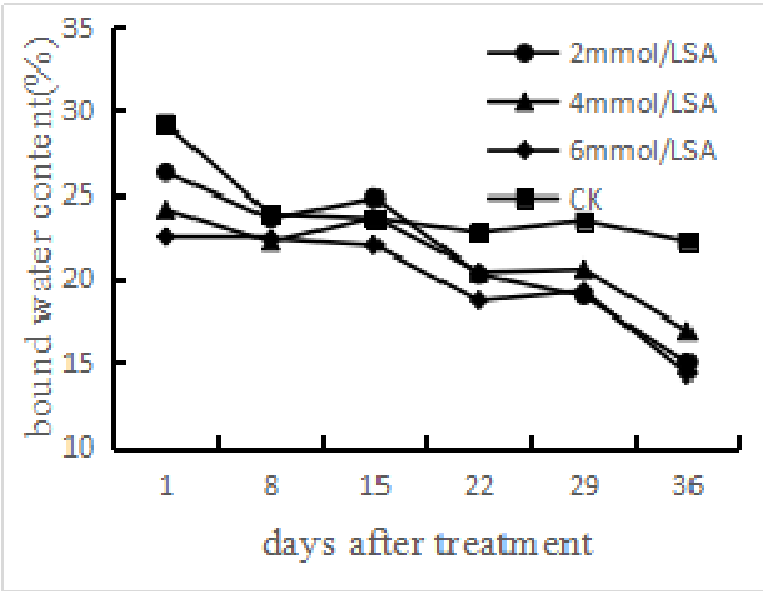

Fig.3 Effects of SA on bound water content

Changes of Organic Nutrients. The soluble sugar content decreased first and then increased, and that in the experimental group was higher than that in CK (Fig.2). It can be seen from the figure 2 that the soluble sugar content reaches the lowest value on the 15 day after treatment, which means that the forced dormancy was ended at this time. The increasing of soluble sugar content may be related to the gradual enhancement of respiration. Soluble sugar acts as an energetic material.

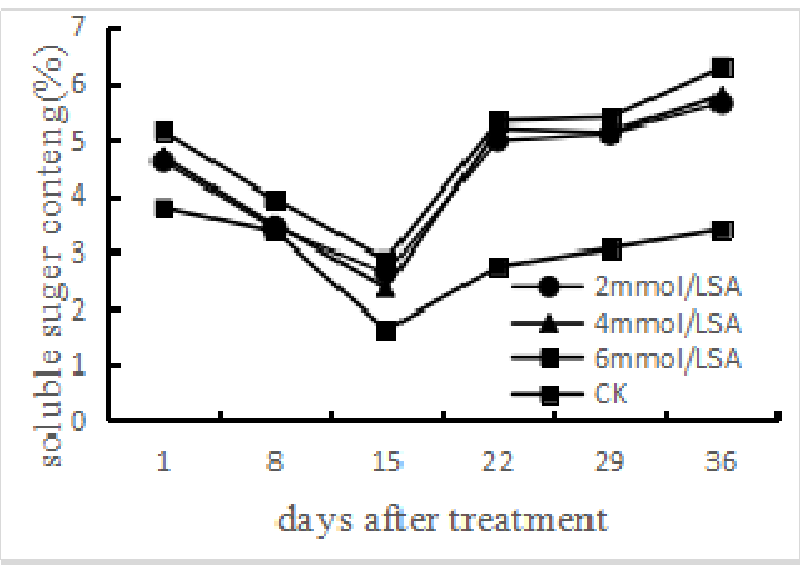

Fig.4 Effects of SA on soluble sugar content.

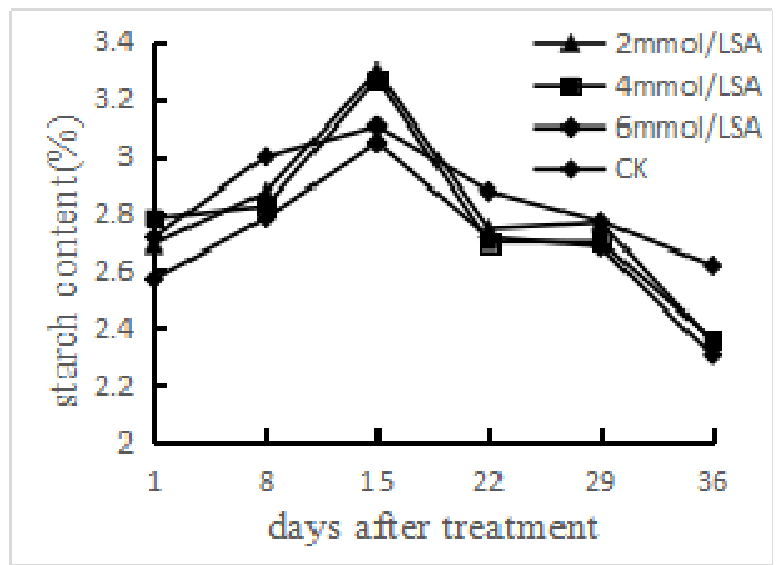

Fig.5 Effects of SA on starch content.

The change trend of starch was opposite to that of soluble sugar. It reaches the peak value on the 15 day after treatment. The starch content of each treatment was always lower than that of CK (Fig.2). Among them, starch content in branches treated by $6 \mathrm{mmol} / \mathrm{L} \mathrm{SA}$ was always lower than that in other concentrations.

During the experiment, soluble protein content in branches increased first and then decreased. When the forced dormancy was breaking on the fifteenth day after treatment, the maximum was reached. The soluble protein content of each experimental group was always lower than that of CK, which may have been caused by the treatment of dormancy-breaking chemicals which inhibited the synthesis of proteins or accelerated the hydrolysis of proteins. 


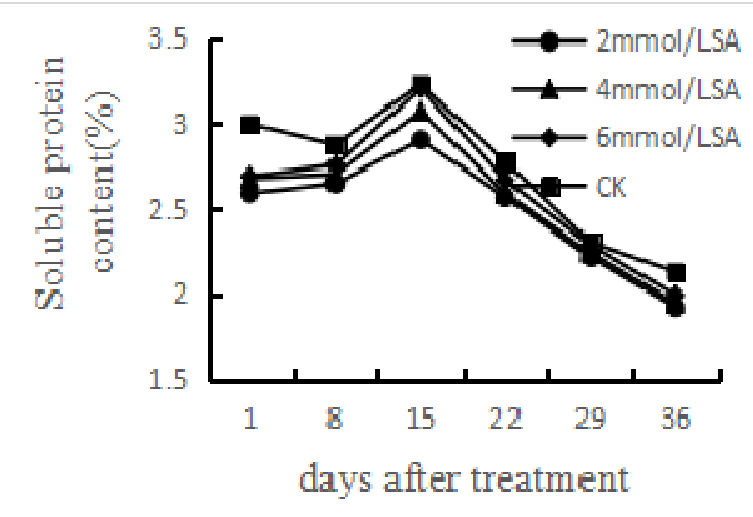

Fig.6 Effects of SA on soluble protein content.

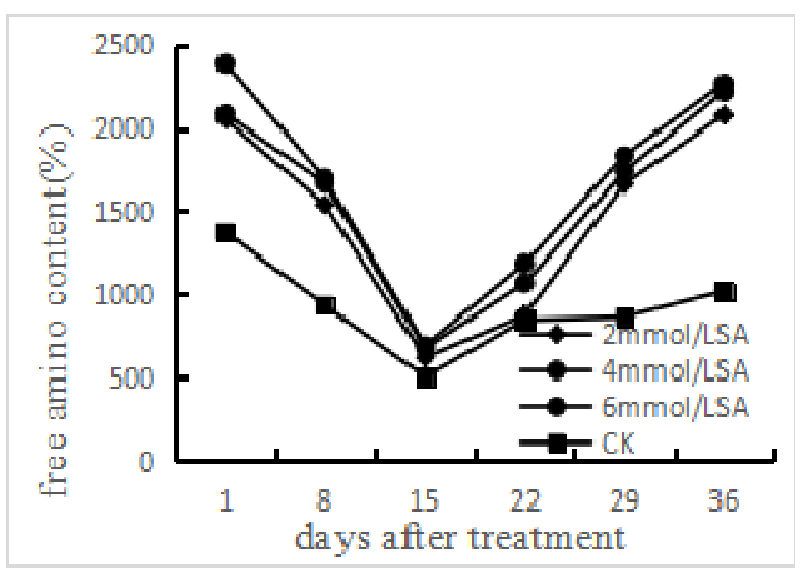

Fig.7 Effects of SA on free amino content.

The content of free amino acids decreased first and then increased. The minimum value was reached on the 15 day after treatment. The content of free amino acids in the experimental group was always higher than that in CK. The high free amino acid content showed that the metabolic activity of the cells was vigorous at this time, and the free amino acids could be used as the basis for the synthesis of macromolecular substances, which promoted the germination of jujube buds.

The Effect of Different Concentrations of SA on Fruit Quality of Jujube. The Vc content of fruits treated by SA had no significant effect on Vc content. The soluble solids (TSS) content of fruit treated by $2 \mathrm{mmol} / \mathrm{L} \mathrm{SA}$ was slightly lower than that of $\mathrm{CK}$, while those treated by $6 \mathrm{mmol} / \mathrm{L}$ SA was increased by $12.2 \%$. The soluble sugar content of all fruits treated by dormancy-breaking chemicals was slightly higher than that of CK. And $4 \mathrm{mmol} / \mathrm{L}$ SA had an increasing of the titratable acid content of the fruit. The single fruit weight of the branches treated by $4 \mathrm{mmol} / \mathrm{L}$ SA was slightly lower than that of CK, but the difference was not significant. In all treatments, the single fruit weight of the branches treated by $6 \mathrm{mmol} / \mathrm{L}$ SA was the largest. However, because the single fruit weight of fruit is greatly influenced by tree vigor and loading capacity, it is difficult to evaluate the effect of treatment.

Table 1 Effects of different concentrations of SA on single fruit weight of jujube

\begin{tabular}{|c|c|c|c|c|c|}
\hline Treatment & $\begin{array}{c}\text { Vc } \\
(\mathrm{mg} / 100 \mathrm{~g})\end{array}$ & $\begin{array}{c}\text { TSS } \\
(\%)\end{array}$ & $\begin{array}{c}\text { Soluble sugar } \\
(\%)\end{array}$ & $\begin{array}{c}\text { Per fruit weght } \\
(\mathrm{g})\end{array}$ & $\begin{array}{c}\text { titratable acid } \\
(\mathrm{g} / 100 \mathrm{ml})\end{array}$ \\
\hline $2 \mathrm{mmol} / \mathrm{L} \mathrm{SA}$ & $436.15 \pm 0.06 \mathrm{a}$ & $19.1 \pm 0.24 \mathrm{a}$ & $24.673529 \pm 0.05 \mathrm{a}$ & $4.6865 \pm 0.07 \mathrm{a}$ & $0.5376 \pm 0.02 \mathrm{c}$ \\
\hline $4 \mathrm{mmol} / \mathrm{L} \mathrm{SA}$ & $404.43 \pm 0.13 \mathrm{~b}$ & $21.2 \pm 0.07 \mathrm{~b}$ & $24.261765 \pm 0.08 \mathrm{a}$ & $4.552 \pm 0.11 \mathrm{c}$ & $0.64512 \pm 0.06 \mathrm{a}$ \\
\hline $6 \mathrm{mmol} / \mathrm{L} \mathrm{SA}$ & $444.08 \pm 0.09 \mathrm{a}$ & $22.1 \pm 0.15 \mathrm{c}$ & $22.408824 \pm 0.14 \mathrm{~b}$ & $4.7575 \pm 0.08 \mathrm{~b}$ & $0.5376 \pm 0.07 \mathrm{c}$ \\
\hline $\mathrm{CK}$ & $340.99 \pm 0.21 \mathrm{c}$ & $19.7 \pm 0.13 \mathrm{a}$ & $19.702941 \pm 0.17 \mathrm{c}$ & $4.6255 \pm 0.15 \mathrm{a}$ & $0.6144 \pm 0.12 \mathrm{~b}$ \\
\hline
\end{tabular}

Note: average \pm standard deviation.

\section{Conclusions}

In the process of forced dormancy of Z. jujuba 'Zhanshanmizao' buds, the change trend of free water and bound water was opposite, and the change trend of soluble sugar and starch was opposite. The increase of free water content may be caused by the transformation of bound water. The hydrolysis of starch may lead to an increase of soluble sugar content. The ratio of free water to bound water 
increases and the hydrolysis of starch may be related to the release of forced dormancy. During the period of forced dormancy, the soluble protein synthesis ability of Zhanshan jujube buds increased and the content of free amino acids decreased. When forced dormancy was relieved, soluble protein content will be decreased, free amino acid content will be increased, and the metabolic activity of the bud will be enhanced. The research results were similar to those of Simões et al. [9]. It could be inferred that the forced dormancy of Zhanshan jujube buds in CK was relieved on the 15 day after the experiment, and the effect of different concentrations of SA to break the dormancy of Zhanshan jujube was different.

During the period of forced dormancy, the application of dormancy-breaking chemicals had little effect on the quality of Zhanshan jujube fruits. The sugar-acid ratio of all the branches and fruits treated by dormancy-breaking chemicals increased to a certain extent, among which the sugar-acid ratio of the branches treated by $2 \mathrm{mmol} / \mathrm{L} \mathrm{SA}$ was slightly higher than that of other concentrations. The single fruit weight and TSS content were not significantly different from those of CK. The Vc content of the branches treated with SA has no significant difference of CK.

In conclusion, $6 \mathrm{mmol} / \mathrm{L} \mathrm{SA}$ could significantly increase the ratio of free water and bound water in Z. jujuba 'Zhanshanmizao' buds, rapidly influence the composition of organic nutrients and activate the antioxidant system.

\section{Acknowledgements}

This work was financially supported by the double subject construction plan of Sichuan Agricultural University and special action plan project of science, and technology rich people and strong county of Sichuan Province "Integration and demonstration of key technologies for industrialized development of Zizyphus jujuba 'Zhanshangmizao' of Santai County”.

\section{References}

[1] M.J. Liu, J.R. Wang, P. Liu, J. Zhao, Z.H. Zhao, L. Dai, X.S. Li and Z.G. Liu: Acta Horticulturae Sinica Vol. 42 (2015), p. 16.

[2] Z.Z. Wang: Modern Agricultural Research Vol. 4(2008), p. 4.

[3] W.D. Zhao, H.L. Zhao and D.S. Gao: Northern Horticulture Vol. 5(2008), p. 62

[4] P.Q Sun, J.Liu, J.M. Jia, X.H. Wang, Z.A. Shi and X.L. Li: Chinese Agricultural Science Bulletin Vol. 27(2011), p. 222.

[5] X.X. Li., and J. Z. Li: Storage And Process Vol. 13(2013), p. 24.

[6] H. Cai, R.F. Shen: Acta Pedologica Sinica Vol. 42(2005), p. 306.

[7] L.L. Deng, X.Q. Pan, J.P. Sheng and L. Shen: Food Science Vol. 33(2012), p. 185.

[8] H.R. Gao, J. Zhang, X.L. Chen and M.X. Chen: Journal of Food Safety and Quality Vol. 6(2015), p. 4142.

[9] F. Simões, F.J. Hawerroth, R.R. Yamamoto and F.G. Herter: Acta Horticulturae Vol. 1058(2014), p.305. 